\title{
Metformin-induced B12 deficiency: still relevant today
}

\author{
Mohsin Muhktar $^{1} \cdot$ Dearbhla Sherry $^{2} \cdot$ Laura Keaver $^{2} \cdot$ Catherine M. McHugh $^{1}$
}

Received: 30 May 2019 / Accepted: 18 July 2019 / Published online: 30 July 2019

(C) The Author(s) 2019

\section{Dear Editor,}

With the rising prevalence of type 2 diabetes worldwide, metformin is recommended as first-line pharmacotherapy and use is increasing. $83.6 \%$ of people with type 2 diabetes in the UK in 2013 received metformin [1]. Its long-term use has been reported to be associated with vitamin B12 deficiency secondary to intestinal malabsorption and can elevate homocysteine concentrations and potentially exacerbate preexisting cardiovascular risk factors in type 2 diabetes [2]. However, despite this, there are no national guidelines for B12 screening in those receiving metformin pharmacotherapy.

An audit was conducted to look at the screening practices for serum vitamin $\mathrm{B} 12$ concentrations in people taking metformin being cared for by general practitioners and diabetologists in the North West of Ireland from 2009 to 2018. We also looked to determine if there was a relationship evident between metformin use and B12 deficiency in this cohort (Data was obtained from the Pro-wellness Database ${ }^{\circledR}$, and Sunquest Laboratory Management System $\left({ }^{\circledR}\right)$. Concentrations were assayed using the Roche Cobass ${ }^{\circledR}$ assay (Roche c602 analyzer) with a measurement range of 150-20,000 pg/ml. Insufficiency was defined as a vitamin B12 concentration of $200-300 \mathrm{pg} / \mathrm{ml}$, and deficiency as concentrations $<200 \mathrm{pg} / \mathrm{ml}$.

Two hundred forty-one individual patient records were assessed with 56 of these never having been screened for B12 concentration.

Seventy-three patients had sufficient data available (metformin dosage, start date, B12 levels pre and post treatment) to allow for the relationship between metformin use and B12 concentration to be determined. The mean duration of treat-

Catherine M. McHugh

catherinem.mchugh@hse.ie

1 Department of Endocrinology and Diabetes, Sligo University Hospital, The Mall, Sligo, Republic of Ireland

2 Department of Health and Nutritional Science, Sligo Institute of Technology, Ash Lane, Sligo, Republic of Ireland ment was 38.5 months (range 3.94-126 months), and the mean dose was $1526 \mathrm{mgs}$ daily (range 500 to $3000 \mathrm{mgs}$ daily). There was a reduction in $\mathrm{B} 12$ concentration from baseline in $67.1 \%(n=49)$ of subjects (ranging from 4 to $73 \%)$, reaching levels of deficiency in 12\% $(n=9)$ and insufficiency in $18 \%$ $(n=13)$. The reduction in vitamin B12 concentration was strongly associated with longer duration of treatment $(p=$ 0.04 ), and lower pre-treatment concentrations of vitamin B12 $(p=<0.001)$. There was a correlation between the duration of metformin therapy and the degree of change in vitamin B12 concentration $(p=0.004)$. Anti-intrinsic factor antibody, anti-parietal cell antibody, or homocysteine concentrations were not sampled for any individual.

B12 deficiency appears to be a largely forgotten complication of metformin pharmacotherapy with $23 \%$ of patients having no vitamin B12 concentrations recorded. Admittedly, there is no consensus on the appropriateness of treatment of asymptomatic insufficiency without anemia; however, metaanalyses have previously shown a reduction after 3 to 6 months of usage [3].

The efficacy of oral vitamin B12 supplementation of $1000 \mu \mathrm{g} /$ day is well documented and comparable with intramuscular supplementation, but it continues to be underprescribed. In 1991, it was reported to be "one of medicines best kept secrets" with $0 \%$ awareness among physicians of this treatment option in Minneapolis (USA), rising to only 19\% on repeat sampling in 1996, and by 2007 , only $32 \%$ of physicians reported prescribing it in a Canadian study [4]. Additionally, the atherogenic hyperhomocystinaemia associated with B12 deficiency can be reduced by adequate B12 replacement.

While the focus in the literature remains on new therapies to advance practice, it remains important that we do not forget that which has already been established. In view of the longevity of therapy, co-existing risk factors for neuropathy and cardiovascular disease, the number of people taking this medication, and the comparable efficacy of oral supplementation, it is important to remind clinicians about the need for B12 screening in those patients prescribed metformin. 
Open Access This article is distributed under the terms of the Creative Commons Attribution 4.0 International License (http:// creativecommons.org/licenses/by/4.0/), which permits unrestricted use, distribution, and reproduction in any medium, provided you give appropriate credit to the original author(s) and the source, provide a link to the Creative Commons license, and indicate if changes were made.

\section{References}

1. Sharma M, Nazareth I, Petersen I (2016) Trends in incidence, prevalence and prescribing in type 2 diabetes mellitus between 2000 and 2013 in primary care: a retrospective cohort study. BMJ Open 6: $\mathrm{e} 010210$
2. Hoogeveen EK, Kostense PJ, Beks PJ, Mackaay AJ, Jakobs C, Bouter LM (1998) Hyperhomocysteinemia is associated with an increased risk of cardiovascular disease, especially in non-insulin-dependent diabetes mellitus. Arterioscler Thromb Vasc Biol 18(1): 133-138

3. Chapman LE, Darling AL, Brown JE (2016) Association between metformin and vitamin B12 deficiency in patients with type 2 diabetes: a systematic review and meta-analysis. Diabetes Metab 42(5): 316-327

4. Graham ID, Jette N, Tetroe J, Robinson N, Milne S, Mitchell SL (2007) Oral cobalamin remains medicine's best kept secret. Arch Gerontol Geriatr 44(1):49-59

Publisher's note Springer Nature remains neutral with regard to jurisdictional claims in published maps and institutional affiliations. 